\title{
Role of heart-rate variability in preoperative assessment of physiological reserves in patients undergoing major abdominal surgery
}

This article was published in the following Dove Press journal:

Therapeutics and Clinical Risk Management

19 September 2017

Number of times this article has been viewed

\section{Petr Reimer' \\ Jan Máca' \\ Pavel Szturz' \\ Ondřej Jor' \\ Roman Kula' \\ Pavel Ševčík' \\ Michal Burda ${ }^{2}$ \\ Milan Adamus ${ }^{3}$}

'Department of Anesthesiology and Intensive Care Medicine, University Hospital Ostrava, ${ }^{2}$ Institute for Research and Applications of Fuzzy Modeling, Centre of Excellence IT4Innovations, University of Ostrava, Ostrava, ${ }^{3}$ Department of Anesthesiology and Intensive Care Medicine, University Hospital Olomouc, Olomouc, Czech Republic
Correspondence: Petr Reimer Department of Anesthesiology and Intensive Care Medicine, University Hospital Ostrava, 17 listopadu 1790, Ostrava 708 52, Czech Republic Tel +420 607743923

Email petr.reimer@gmail.com
Background: Major abdominal surgery (MAS) is associated with increased morbidity and mortality. The main objective of our study was to evaluate the predictive value of heart-rate variability (HRV) concerning development of postoperative complications in patients undergoing MAS. The secondary objectives were to identify the relationship of HRV and use of vasoactive drugs during anesthesia, intensive care unit length of stay (ICU-LOS), and hospital length of stay (H-LOS).

Patients and methods: Sixty-five patients scheduled for elective MAS were enrolled in a prospective, single-center, observational study. HRV was measured by spectral analysis (SA) preoperatively during orthostatic load. Patients were divided according to cardiac autonomic reactivity (CAR; $\mathrm{n}=23$ ) and non-cardiac autonomic reactivity (NCAR; $\mathrm{n}=30$ ).

Results: The final analysis included 53 patients. No significant difference was observed between the two groups regarding type of surgery, use of minimally invasive techniques or epidural catheter, duration of surgery and anesthesia, or the amount of fluid administered intraoperatively. The NCAR group had significantly greater intraoperative blood loss than the CAR group $(541.7 \pm 541.9 \mathrm{~mL}$ vs $269.6 \pm 174.3 \mathrm{~mL}, p<0.05)$. In the NCAR group, vasoactive drugs were used during anesthesia more frequently ( $\mathrm{n}=21 \mathrm{vs} \mathrm{n}=4 ; p<0.001)$, and more patients had at least one postoperative complication compared to the CAR group ( $\mathrm{n}=19$ vs $\mathrm{n}=4 ; p<0.01$ ). Furthermore, the NCAR group had more serious complications (Clavien-Dindo $\geq$ Grade III $n=6$ vs $n=0$; $p<0.05$ ) and a greater number of complications than the CAR group ( $\mathrm{n}=57$ vs $\mathrm{n}=5 ; p<0.001$ ). Significant differences were found for two specific subgroups of complications: hypotension requiring vasoactive drugs (NCAR: $\mathrm{n}=10$ vs CAR: $\mathrm{n}=0 ; p<0.01)$ and ileus (NCAR: $\mathrm{n}=11$ vs CAR: $\mathrm{n}=2 ; p<0.05$ ). Moreover, significant differences were found in the ICU-LOS (NCAR: 5.7 \pm 3.5 days vs CAR: $2.6 \pm 0.7$ days; $p<0.0001)$ and H-LOS (NCAR: $12.2 \pm 5.6$ days vs CAR: $7.2 \pm 1.7$ days; $p<0.0001)$.

Conclusion: Preoperative HRV assessment during orthostatic load is objective and useful for identifying patients with low autonomic physiological reserves and high risk of poor postoperative course.

Keywords: heart-rate variability, spectral analysis, orthostatic load, autonomic dysfunction, major abdominal surgery, postoperative complications

\section{Introduction}

A fundamental feature of a healthy organism is continuous communication between vital organs through the autonomic nervous system (ANS). ${ }^{1}$ The ANS is composed of the sympathetic nervous system (SNS) and parasympathetic nervous system (PNS) and plays a crucial role in maintaining homeostasis in response to internal and external stimuli. ${ }^{2}$ Surgical trauma leads to tissue injury and activates inflammatory 
pathways. ${ }^{3}$ The organism responds with complex reactions, leading to structural and functional repair of injured tissues. However, dysregulation of the inflammatory response may aggravate local tissue damage, leading to shock, multiple organ dysfunction syndrome (MODS), and death. ${ }^{4}$ Under physiological conditions, the pro-inflammatory response is balanced by an anti-inflammatory response, including the cholinergic anti-inflammatory pathway of the vagus nerve. ${ }^{5}$ In addition, anesthetics influence cardiovascular homeostasis, and preexisting autonomic dysfunction (AD) can lead to hemodynamic instability during anesthesia. ${ }^{6}$ Preserved autonomic regulation represents adequate physiological reserves and better reactivity to various insults during the perioperative course. $^{7}$

Analysis of heart-rate variability (HRV) - the oscillation of intervals between consecutive heart beats - is an accepted noninvasive method of evaluating the autonomic influence on heart activity. ${ }^{8,9}$ The human organism is a nonlinear biological system characterized by so-called oscillation phenomena. The oscillations originate from a neurally mediated organ interaction. The disturbance in variations of oscillations may show the beginning of, or advanced, deterioration of organ systems. HRV is an objective method for possibly evaluating this phenomena. ${ }^{1,8}$ In our study, we used spectral analysis of HRV, which is a linear method, that simplified the biosignal of HRV. However, some autonomic challenges, such as orthostatic load or the Valsalva maneuver, can improve the sensitivity of ANS assessment and better reflect the real autonomic physiological reserves of patients. ${ }^{10,11}$

AD represented by reduced HRV is widely accepted as an independent adverse prognostic factor in various pathological conditions (eg, myocardial infarction, coronary artery disease, congestive heart failure, diabetes mellitus, MODS). ${ }^{12-16} \mathrm{AD}$ may negatively influence the perioperative course due to hemodynamic instability during anesthesia, thus increasing postoperative morbidity and mortality. ${ }^{17}$ The link between low HRV and worse surgical outcome has been confirmed by several studies. ${ }^{18-27}$ Nevertheless, routine assessment of HRV by anesthesiologists is still rare. ${ }^{28}$

The main goal of our study was to investigate the relationship between spectral analysis of HRV during orthostatic load with postsurgical outcome in patients scheduled for elective major abdominal surgery (MAS). The primary endpoint was the occurrence of postoperative complications, according to the Clavien-Dindo classification. ${ }^{29,30}$ Secondary endpoints were evaluation of HRV as a predictor of the need for vasoactive drugs during anesthesia, intensive care length of stay (ICU-LOS), and hospital length of stay (H-LOS).

\section{Materials and methods}

This prospective observational study was approved by the Institutional Ethics Committee of the University Hospital Ostrava (ref no 606/2014) and registered at ClinicalTrials.gov (Identifier NCT02375412). Written informed consent was signed by all enrolled patients. The study was conducted between February 2015 and December 2016 at University Hospital Ostrava, Czech Republic. We enrolled 65 patients scheduled for elective MAS. The exclusion criteria were: emergency or acute surgery, absence of sinus rhythm, American Society of Anesthesiologists (ASA) physical status I, and age $<18$ years. Standard baseline demographic and clinical data were collected before surgery.

HRV was measured in a quiet, mildly illuminated room, at room temperature $22^{\circ} \mathrm{C}-24^{\circ} \mathrm{C}$, between $14: 00$ and 17:00 the day before the surgery. Short-term spectral analysis of HRV was conducted according to Task Force recommendations using a DiANS PF8 diagnostic system (Olomouc, Czech Republic). ${ }^{31}$ The R-R intervals on the electrocardiogram were recorded with a sampling rate of $1,000 \mathrm{~Hz}$, and the acquired data were automatically filtered in order to eliminate ectopic beats or artifacts using the recognition algorithm, as verified manually. The intervals were analyzed using modified fast Fourier transformation (FFT). Recordings were obtained in three consecutive positions (supine-1, standing, and supine-2), each lasting 300 seconds. The first supine position (supine-1) was an adaptive one, the active standing position (standing) represents autonomic load, and another supine position (supine-2) is the final position for an overall evaluation of the spectral parameters of HRV. ${ }^{9,32}$ The final results were displayed in the form of a three-dimensional chart of HRV patterns. This HRV analysis allowed a visual overview of HRV dynamics and improved the evaluation of cardiac autonomic reactivity.

In addition to the visual representation, the following parameters of frequency (spectral) domain were calculated in every position: (1) spectral power of low frequency (LF; $0.05-0.15 \mathrm{~Hz}$ ), reflecting a combination of sympathetic and parasympathetic effects on cardiac autonomic tone; ${ }^{33}$ (2) spectral power of high frequency ( $\mathrm{HF}$; $0.15-0.4 \mathrm{~Hz}$ ) corresponding exclusively to parasympathetic tone; ${ }^{34}$ (3) total spectral power (TP; 0.05-0.4 Hz), representing the main outcome variables in both frequency bands ( $\mathrm{LF}+\mathrm{HF})$; and (4) the LF to HF ratio ( $\mathrm{LF} / \mathrm{HF}$ ), representing the index of sympathovagal interaction. ${ }^{35}$ Spectral indexes were expressed both in absolute values $\left(\mathrm{ms}^{2}\right)$ and natural logarithm (ln). For the final evaluation of HRV, we used the TP from the supine- 2 position. Patients were divided into two 


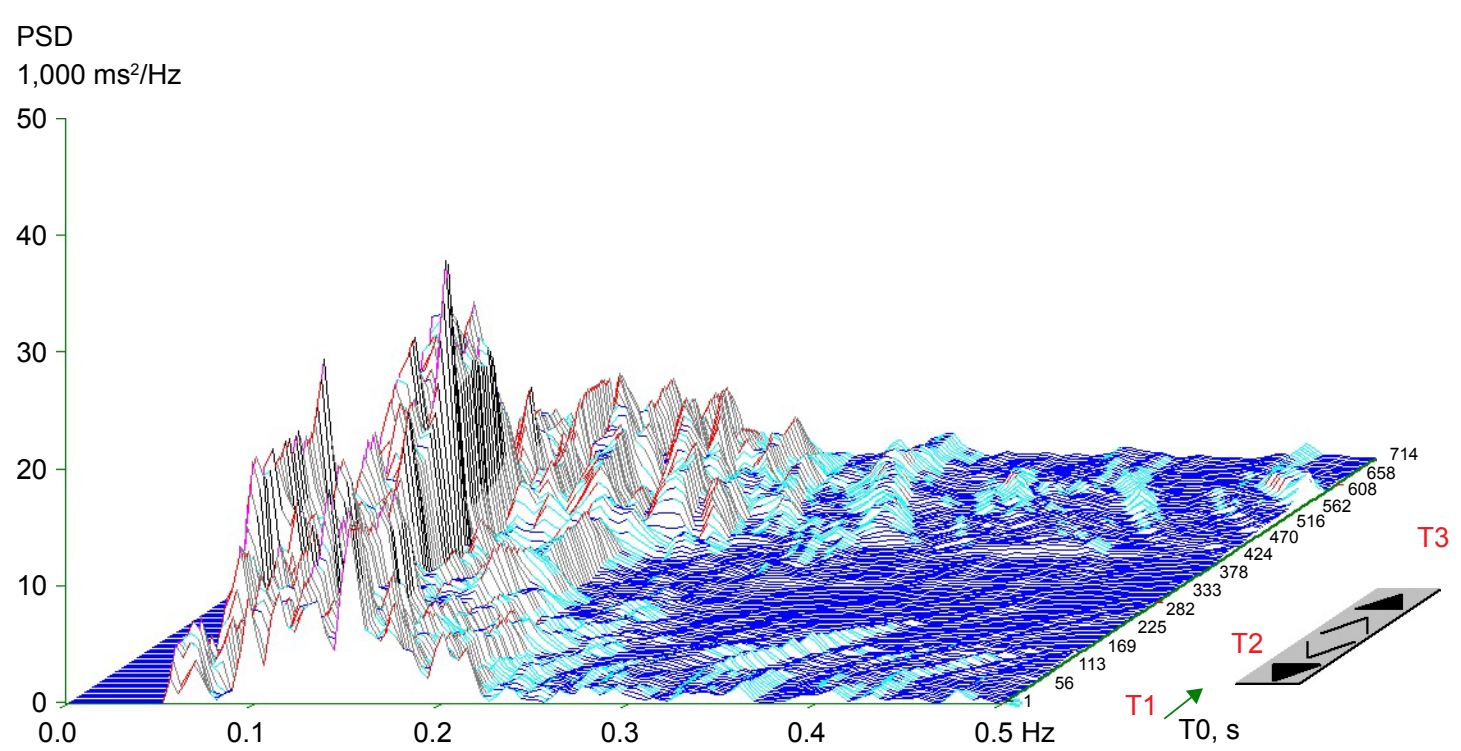

Figure I Typical three-dimensional chart of a spectral analysis of heart-rate variability during orthostatic load in the cardiac autonomic reactivity group.

Notes: Standing augmented the low-frequency power $(0.05-0.15 \mathrm{~Hz})$ and reduced the high-frequency power $(0.15-0.4 \mathrm{~Hz})$ in T2 due to baroreceptor unloading and reduced vagal activity. High-frequency power was augmented in the repeated supine position in T3. The frequency of fluctuations in $\mathrm{R}-\mathrm{R}$ intervals ( $\mathrm{Hz}$ ) is given on the $\mathrm{X}$-axis; power spectral density (PSD; $\mathrm{ms}^{2} / \mathrm{Hz}$ ) on the $\mathrm{y}$-axis; and time (s) on the z-axis. TI: supine-I, T2: standing, T3: supine-2.

groups: cardiac autonomic reactivity (CAR), characterized by a calculated TP (supine-2) $\geq 200 \mathrm{~ms}^{2}$ and a chart with peaks of spectral energy in a particular frequency band (Figure 1), and non-cardiac autonomic reactivity (NCAR), characterized by TP $<200 \mathrm{~ms}^{2}$ and a plain chart due to a reduction in overall spectral power (Figure 2).

Anesthetic and surgical techniques were carried out in a standardized manner. Surgical procedures were undertaken under general anesthesia (GA) or a combination of general and epidural anesthesia. GA was induced by the administration of sufentanil, propofol, and cis-atracurium Sevoflurane in an oxygen/air mixture was added to maintain balanced anesthesia. Mechanical ventilation was standardized (6-8 $\mathrm{mL} / \mathrm{kg}$ predicted body weight, PEEP 5-7 $\mathrm{cm} \mathrm{H}_{2} \mathrm{O}$ ). Anesthesia management (ie, use of balanced crystalloids, blood products, and vasoactive drugs) was left to the discretion of the anesthesiologist. Intraoperative data such as the duration of the procedure, fluid intake, output, and the use of vasoactive drugs were recorded. All patients were transferred to the ICU after the surgical procedure.

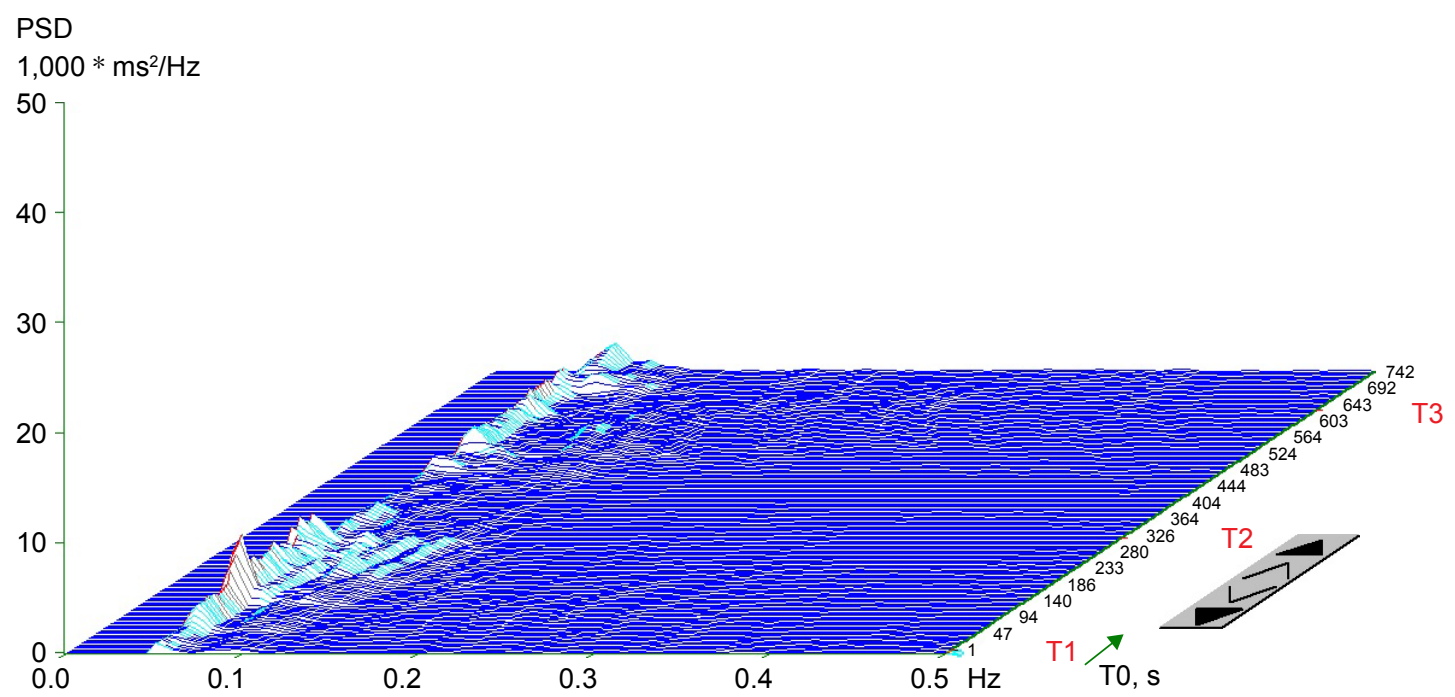

Figure 2 Typical plain three-dimensional chart of a spectral analysis of heart-rate variability during orthostatic load in the non-cardiac autonomic reactivity group. Notes: The frequency of fluctuations in R-R intervals $(\mathrm{Hz})$ is given on the $\mathrm{x}$-axis; power spectral density (PSD; ms $\left.{ }^{2} / \mathrm{Hz}\right)$ on the $y$-axis; and time (s) on the $\mathrm{z}$-axis. TI: supine-I, T2: standing, T3: supine-3. 
Complications were defined as any postoperative process that was not part of normal recovery during the postoperative period. These complications were classified according to the Clavien-Dindo classification. Grades I and II are defined as any deviation from the normal postoperative course without need for surgical, endoscopic, or radiological intervention (Grade I), with Grade II including a need for pharmacological treatment; Grade III requires a surgical, endoscopic, or radiological intervention without (Grade IIIa) or with GA (Grade IIIb); Grade IV includes single-organ failure requiring ICU care (Grade IVa) or multiple organ failure (Grade IVb); and Grade V is characterized by the patient's death. ${ }^{29} \mathrm{We}$ recorded the most severe grade of complications for each patient according to recommendations. ${ }^{30}$ Moreover, the complications were divided into two subgroups: minor (Grade I and Grade II) and major (Grade $\geq$ III). All complications encountered in our study were recorded.

\section{Statistical analysis}

For numerical data, the arithmetic mean \pm standard deviation (SD) was computed. Categorical data were summarized by absolute count and relative frequency (\%). Differences between the CAR and NCAR were assessed using the $t$-test (numerical data) or Fisher exact test (categorical data). All statistical analyses, figures, and tables were created by a certified statistician (co-author MB) using R software (version 3.3.3). The level of significance was defined as $p \leq 0.05$.

\section{Results}

Sixty-five patients were screened for the study. We excluded 12 patients from further analysis due to cancellation of the operative procedures $(n=2)$, technically inadequate recordings (artifacts or excessive ectopic beats, $n=7$ ), and missing data during the postoperative period $(n=3)$. Therefore, the final study population comprised 53 patients; see the CONSORT flow diagram (Figure 3). No significant differences were found between groups with regard to demographic characteristics. We found some significant differences in medical history between the CAR and NCAR (myocardial infarction: $\mathrm{n}=0$ vs $\mathrm{n}=6, p<0.05$; diabetes mellitus: $\mathrm{n}=1$ vs $\mathrm{n}=11, p<0.01$; and hyperlipidemia: $\mathrm{n}=4$ vs $\mathrm{n}=18, p<0.01$, respectively). These differences in comorbidities were reflected by differences in chronic medications between the CAR and NCAR (per oral antidiabetics: $n=0$ vs

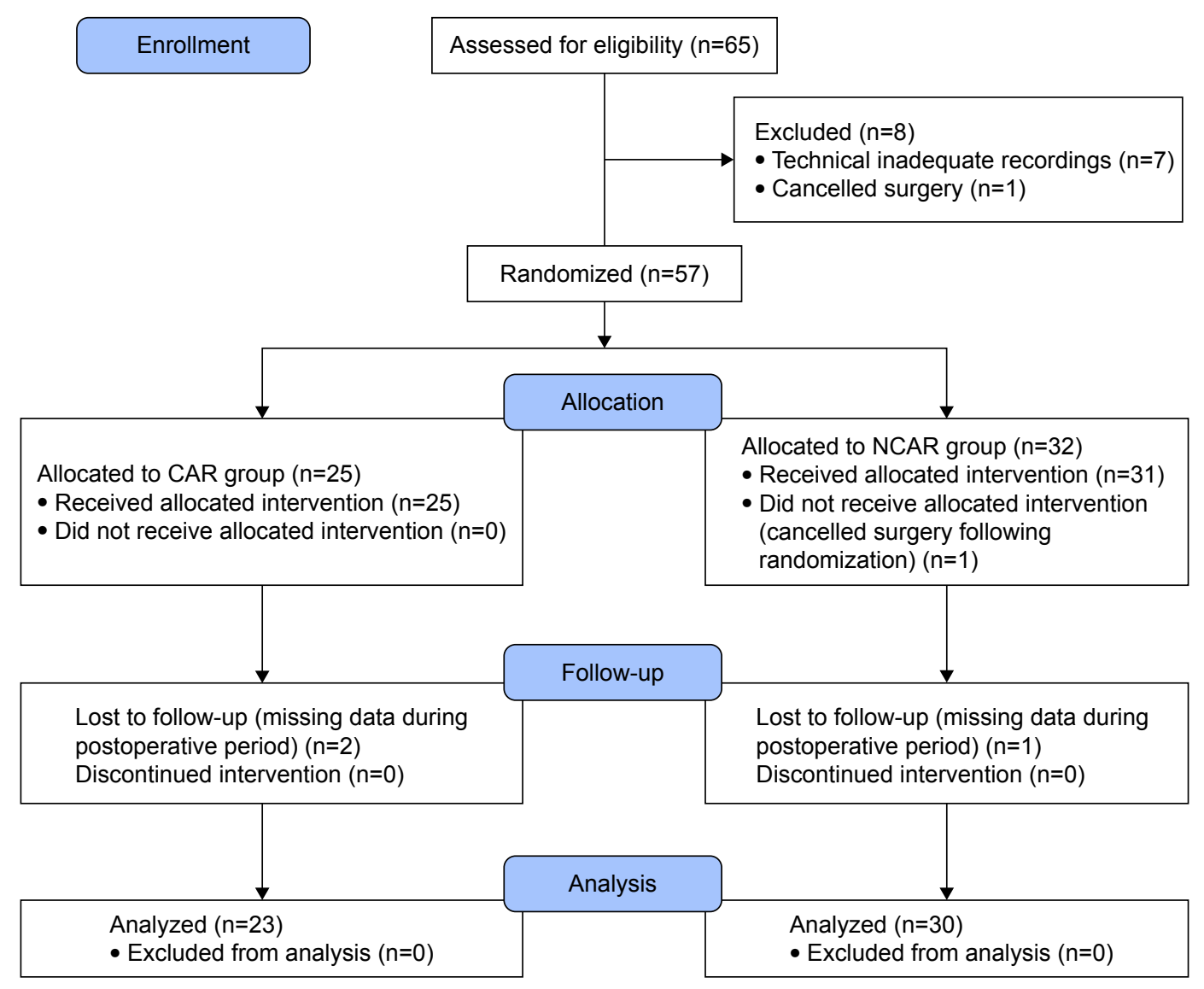

Figure 3 CONSORT flow diagram.

Abbreviations: CAR, cardiac autonomic reactivity; NCAR, non-cardiac autonomic reactivity. 
$\mathrm{n}=7, p<0.05$; statins: $\mathrm{n}=3$ vs $\mathrm{n}=14, p<0.05$, respectively). We also found that a significantly greater proportion of patients in the CAR had ASA II than the NCAR (78\% vs 47\%, $p<0.05$; Table 1).

Cardiac autonomic reactivity during orthostatic load was observed in 23 patients (CAR) and a reduced autonomic response was observed in 30 patients (NCAR). Significant differences were found between study groups in all calculated spectral power indices of HRV expressed in absolute values $\left(\mathrm{ms}^{2}\right)$ and natural logarithm $(\mathrm{LN})$ values in all three measurement positions during orthostatic load $(p<0.0001)$. The LF/HF ratio was significantly different in only supine-1 $(p<0.05$; Table 2$)$.

Table I Patient characteristics

\begin{tabular}{|c|c|c|c|}
\hline Characteristics & CAR & NCAR & $p$-value \\
\hline Number of patients & 23 & 30 & \\
\hline \multicolumn{4}{|l|}{ Demographic data } \\
\hline Age, years & $64.8 \pm 8.4$ & $69.4 \pm 8.2$ & NS* \\
\hline Sex, male/female & $16 / 7$ & $22 / 8$ & NS \\
\hline Body weight, kg & $80.4 \pm 13.3$ & $81.5 \pm 11.2$ & NS \\
\hline Height, cm & $172.3 \pm 8.4$ & $172.2 \pm 8.6$ & NS \\
\hline $\mathrm{BMI}, \mathrm{kg} / \mathrm{m}^{2}$ & $27.0 \pm 3.5$ & $27.7 \pm 3.6$ & NS \\
\hline $\mathrm{BSA}, \mathrm{m}^{2}$ & $1.9 \pm 0.2$ & $2.0 \pm 0.2$ & NS \\
\hline \multicolumn{4}{|l|}{ Medical conditions } \\
\hline Hypertension & $14(61)$ & $25(83)$ & NS \\
\hline Coronary artery disease & $2(9)$ & $8(27)$ & NS \\
\hline Chronic heart failure & $0(0)$ & $2(7)$ & NS \\
\hline History of MI & $0(0)$ & $6(20)$ & 0.0303 \\
\hline Atrial fibrillation & $3(13)$ & $3(10)$ & NS \\
\hline Diabetes mellitus & I (4) & II (37) & $0.007 \mid$ \\
\hline Chronic renal failure & $0(0)$ & $2(7)$ & NS \\
\hline COPD & I (4) & $5(17)$ & NS \\
\hline Hyperlipidemia & $4(17)$ & $18(60)$ & 0.0022 \\
\hline \multicolumn{4}{|l|}{ Medication } \\
\hline B-adrenergic blockers & $10(43)$ & $12(40)$ & NS \\
\hline ACE inhibitors & $7(30)$ & II (37) & NS \\
\hline ARBs & I (4) & $6(20)$ & NS \\
\hline $\mathrm{CCBs}$ & $4(17)$ & $12(40)$ & NS \\
\hline Diuretics & $5(22)$ & $8(27)$ & NS \\
\hline Aspirin & $3(13)$ & $8(27)$ & NS \\
\hline Anticoagulants & I (4) & $5(17)$ & NS \\
\hline Oral antidiabetics & $0(0)$ & $7(23)$ & 0.0148 \\
\hline Insulin & $0(0)$ & $4(13)$ & NS \\
\hline Statins & $3(13)$ & $14(47)$ & 0.0163 \\
\hline \multicolumn{4}{|l|}{ ASA } \\
\hline II & $18(78)$ & $14(47)$ & 0.0255 \\
\hline III & $5(22)$ & $14(47)$ & NS \\
\hline IV & $0(0)$ & $2(7)$ & NS \\
\hline
\end{tabular}

Notes: Data are presented as mean \pm standard deviation or $\mathrm{n}(\%)$ unless otherwise noted. $* p>0.05$.

Abbreviations: NS, not significant; CAR, cardiac autonomic reactivity; NCAR, non-cardiac autonomic reactivity; BMI, body mass index; BSA, body surface area; $\mathrm{MI}$, myocardial infarction; COPD, chronic obstructive pulmonary disease; $A C E$, angiotensin-converting enzyme; ARBs, angiotensin II receptor blockers; CCBs, calcium channel blockers; ASA, American Association of Anesthesiologists physical status classification system.
Table 2 Intergroup comparison of parameters in a frequency domain analysis of heart-rate variability during orthostatic load (supine-I-standing-supine-2)

\begin{tabular}{|c|c|c|c|}
\hline Spectral power & CAR & NCAR & $p$-value \\
\hline \multicolumn{4}{|l|}{ Supine-I } \\
\hline Power LF, $\mathrm{ms}^{2}$ & $243.4 \pm 140.7$ & $59.0 \pm 39.3$ & $<0.0001$ \\
\hline Power LF, $\ln \left(\mathrm{ms}^{2}\right)$ & $5.3 \pm 0.6$ & $3.7 \pm 1.0$ & $<0.0001$ \\
\hline Power HF, $\mathrm{ms}^{2}$ & $183.5 \pm 106.4$ & $32.6 \pm 20.3$ & $<0.0001$ \\
\hline Power HF, $\ln \left(\mathrm{ms}^{2}\right)$ & $5.1 \pm 0.6$ & $3.2 \pm 0.8$ & $<0.0001$ \\
\hline Total power, $\mathrm{ms}^{2}$ & $426.9 \pm 233.8$ & $91 \pm 53.9$ & $<0.0001$ \\
\hline Total power, $\ln \left(\mathrm{ms}^{2}\right)$ & $5.9 \pm 0.5$ & $4.3 \pm 0.7$ & $<0.0001$ \\
\hline $\mathrm{LF} / \mathrm{HF}$ & $1.4 \pm 0.6$ & $2.2 \pm 1.8$ & 0.0361 \\
\hline \multicolumn{4}{|l|}{ Standing } \\
\hline Power LF, $\mathrm{ms}^{2}$ & $259.1 \pm 145.4$ & $51.7 \pm 39.9$ & $<0.0001$ \\
\hline Power LF, $\ln \left(\mathrm{ms}^{2}\right)$ & $5.4 \pm 0.6$ & $3.7 \pm 0.8$ & $<0.0001$ \\
\hline Power HF, ms² & $93.4 \pm 42.4$ & $21.2 \pm 19.5$ & $<0.0001$ \\
\hline Power HF, $\ln \left(m s^{2}\right)$ & $4.4 \pm 0.5$ & $2.7 \pm 0.9$ & $<0.0001$ \\
\hline Total power, $\mathrm{ms}^{2}$ & $352.5 \pm 166.3$ & $72.9 \pm 53.0$ & $<0.000$ I \\
\hline Total power, $\ln \left(\mathrm{ms}^{2}\right)$ & $5.8 \pm 0.5$ & $4.1 \pm 0.7$ & $<0.0001$ \\
\hline $\mathrm{LF} / \mathrm{HF}$ & $3.2 \pm 2.0$ & $3.9 \pm 3.5$ & NS* \\
\hline \multicolumn{4}{|l|}{ Supine-2 } \\
\hline Power LF, $\mathrm{ms}^{2}$ & $224.3 \pm 118.2$ & $55.8 \pm 28.6$ & $<0.0001$ \\
\hline Power LF, $\ln \left(\mathrm{ms}^{2}\right)$ & $5.2 \pm 0.7$ & $3.8 \pm 0.8$ & $<0.0001$ \\
\hline Power HF, ms ${ }^{2}$ & $208.5 \pm 98.5$ & $43.5 \pm 26.4$ & $<0.0001$ \\
\hline Power HF, $\ln \left(\mathrm{ms}^{2}\right)$ & $5.2 \pm 0.5$ & $3.5 \pm 0.8$ & $<0.0001$ \\
\hline Total power, $\mathrm{ms}^{2}$ & $432.9 \pm 156.3$ & $99.4 \pm 45.5$ & $<0.0001$ \\
\hline Total power, $\ln \left(\mathrm{ms}^{2}\right)$ & $6.0 \pm 0.4$ & $4.4 \pm 0.7$ & $<0.000$ I \\
\hline LF/HF & $1.3 \pm 0.8$ & $1.7 \pm 1.5$ & NS \\
\hline
\end{tabular}

Notes: Data are presented as mean \pm standard deviation. ${ }^{*} p>0.05$.

Abbreviations: CAR, cardiac autonomic reactivity; HF, high frequency; LF, low frequency; NCAR, non-cardiac autonomic reactivity; NS, not significant.

With regarding intraoperative characteristics, no difference was observed between groups for the type of surgery, use of minimally invasive techniques, use of an epidural catheter, amount of intraoperative fluids, and duration of surgery and anesthesia. However, we found significant differences in blood loss $(269.6 \pm 174.3 \mathrm{~mL}$ vs $541.7 \pm 541.9 \mathrm{~mL}$, $p<0.05)$ and the use of at least one vasoactive drug $(\mathrm{n}=4$ vs $\mathrm{n}=21, p<0.001$, Table 3 ) between the CAR and NCAR, respectively.

The number of patients with at least one complication was significantly lower in the CAR than the NCAR ( $n=4$ vs $\mathrm{n}=19, p=0.001)$ group. In addition, significant differences were found in Clavien-Dindo classification Grade II (CAR, $\mathrm{n}=2$ vs NCAR, $\mathrm{n}=12, p<0.05$ ) and Grade $\geq$ III (CAR, $\mathrm{n}=0$ vs NCAR, $\mathrm{n}=6 ; p<0.05$; Table 4). Analyzing the frequency of particular types of complications, we found a significant difference in the occurrence of hypotension requiring vasoactive drugs $(\mathrm{CAR}, \mathrm{n}=0$ vs NCAR, $\mathrm{n}=10, p<0.05)$ as well as ileus (CAR, $\mathrm{n}=2$ vs NCAR, $\mathrm{n}=11, p<0.05$ ). Finally, the overall number of complications was significantly lower in the CAR than the NCAR group ( $\mathrm{n}=5$ vs $\mathrm{n}=57, p<0.001$, Table 5). 
Table 3 Intraoperative characteristics

\begin{tabular}{|c|c|c|c|}
\hline Characteristics & CAR & NCAR & p-value \\
\hline \multicolumn{4}{|l|}{ Type of surgery } \\
\hline Colon resection & $13(57)$ & 14 (47) & NS* \\
\hline Low anterior resection & $10(43)$ & $16(53)$ & NS \\
\hline Minimally invasive technique & $17(74)$ & $20(67)$ & NS \\
\hline Epidural catheter & $20(87)$ & $22(73)$ & NS \\
\hline Blood loss, mL & $269.6 \pm 174.3$ & $541.7 \pm 541.9$ & 0.0140 \\
\hline PRBCs & $0(0)$ & $5(17)$ & NS \\
\hline FFP & $0(0)$ & $5(17)$ & NS \\
\hline Intraoperative fluids, $\mathrm{mL}$ & $2,269.6 \pm 493.1$ & $2,256.7 \pm 598.1$ & NS \\
\hline Urine output, $\mathrm{mL}$ & $489.1 \pm 254.9$ & $510.0 \pm 242.6$ & NS \\
\hline At least one vasoactive drug & $4(17)$ & $21(70)$ & 0.0002 \\
\hline Dobutamine & $3(13)$ & $9(30)$ & NS \\
\hline Noradrenalin & $2(9)$ & $20(67)$ & $<0.0001$ \\
\hline Duration of surgery, minutes & $189.6 \pm 63.5$ & $191.7 \pm 59.5$ & NS \\
\hline Duration of anesthesia, minutes & $211.5 \pm 64.8$ & $213.3 \pm 60.1$ & NS \\
\hline
\end{tabular}

Notes: Data are presented as mean \pm standard deviation or $n(\%)$. ${ }^{*} p>0.05$. Abbreviations: CAR, cardiac autonomic reactivity; FFP, fresh frozen plasma; NCAR, non-cardiac autonomic reactivity; NS, not significant; PRBCs, packed red blood cells.

Concerning outcomes, ICU-LOS and H-LOS were significantly lower in the CAR than the NCAR group (2.6 \pm 0.7 days vs $5.7 \pm 3.5$ days $[p<0.0001]$ and $7.2 \pm 1.7$ days vs $12.2 \pm 5.6[p<0.0001]$, respectively; Table 4$)$.

\section{Discussion}

Our study used a dynamic autonomic test (orthostatic load) for preoperative assessment of HRV to identify patients with reduced autonomic physiological reserves undergoing elective MAS. Our findings clearly show a higher occurrence of postoperative complications, higher hemodynamic instability during anesthesia, and prolonged ICU-LOS and H-LOS in

Table 4 Postoperative complications according to the ClavienDindo classification and length of stay

\begin{tabular}{|c|c|c|c|}
\hline Classification & CAR & NCAR & $p$-value \\
\hline Minor (I+II) & $4(17)$ & $13(43)$ & NS* \\
\hline 1 & $2(9)$ & I (3) & NS \\
\hline ॥ & $2(9)$ & $12(40)$ & 0.0129 \\
\hline Major ( $\geq I I I)$ & $0(0)$ & $6(20)$ & 0.0303 \\
\hline IIla & $0(0)$ & $0(0)$ & NS \\
\hline Illb & $0(0)$ & I (3) & NS \\
\hline $\mathrm{IVa}$ & $0(0)$ & $2(7)$ & NS \\
\hline $\mathrm{IVb}$ & $0(0)$ & I (3) & NS \\
\hline V & $0(0)$ & $2(7)$ & NS \\
\hline At least one complication & $4(17)$ & $19(63)$ & 0.0010 \\
\hline ICU-LOS, days & $2.6 \pm 0.7$ & $5.7 \pm 3.5$ & $<0.0001$ \\
\hline H-LOS, days & $7.2 \pm 1.7$ & $12.2 \pm 5.6$ & $<0.0001$ \\
\hline
\end{tabular}

Notes: Data are presented as mean \pm standard deviation or $n(\%) .{ }^{*} p>0.05$. Abbreviations: CAR, cardiac autonomic reactivity; H-LOS, hospital length of stay; ICU-LOS, intensive care length of stay; NCAR, non-cardiac autonomic reactivity; NS, not significant.
Table 5 Complications encountered in the study

\begin{tabular}{llll}
\hline Complications & CAR & NCAR & p-value \\
\hline Infection & & & \\
$\quad$ Lung & $0(0)$ & $3(10)$ & NS* \\
Abdominal & $0(0)$ & $3(10)$ & NS \\
Urinary tract & $0(0)$ & $2(7)$ & NS \\
Central venous catheter & $0(0)$ & I (3) & NS \\
Wound & I (4) & $3(10)$ & NS \\
Cardiac & & & \\
Arrhythmia & I (4) & $4(13)$ & NS \\
Hypotension requiring vasoactive drugs & $0(0)$ & $10(33)$ & 0.0029 \\
Heart failure & $0(0)$ & $1(3)$ & NS \\
Respiratory failure requiring intubation & $0(0)$ & $3(10)$ & NS \\
Acute kidney injury & $0(0)$ & $4(13)$ & NS \\
Abdominal & & & \\
Ileus & $2(9)$ & II (37) & 0.0252 \\
Gastrointestinal bleeding & $0(0)$ & $2(7)$ & NS \\
Leak anastomosis & $0(0)$ & $3(10)$ & NS \\
Delirium & I (4) & $5(17)$ & NS \\
Sepsis & $0(0)$ & $2(7)$ & NS \\
Death & $0(0)$ & $2(7)$ & NS \\
Total number of complications & 5 & 57 & 0.0006 \\
\hline
\end{tabular}

Notes: Data are presented as $n(\%) .{ }^{*} p>0.05$.

Abbreviations: CAR, cardiac autonomic reactivity; NCAR, non-cardiac autonomic reactivity; NS, not significant.

patients with low autonomic reserves (NCAR). Therefore, we confirmed that patients with $\mathrm{AD}$ are at risk of an adverse intraoperative and postoperative course.

The NCAR patients had a plain spectral analysis for HRV without reactivity during orthostatic load, and all of their calculated parameters were reduced. The reduction in HRV parameters was similar to the identification of diabetic cardiovascular autonomic neuropathy (CAN). ${ }^{36}$ CAN is an accepted risk factor for intraoperative hemodynamic instability and increased occurrence of postoperative cardiovascular events, including sudden death. ${ }^{37,38} \mathrm{CAN}$ is a complication not only of diabetes mellitus, but also of other comorbidities, including chronic coronary disease, chronic heart failure, hypertension, and chronic obstructive pulmonary disease. Neurological and psychiatric disorders have some degree of AD..$^{6-8,12-17}$ In our study, the NCAR group comprised patients with more chronic comorbidities than in the CAR group. We found that $\mathrm{AD}$ reflected both the number and severity of illnesses in the NCAR group. These findings were confirmed by an assessment of ASA; the NCAR group comprised more patients with ASA III and IV than the CAR group, which comprised predominantly ASA II patients.

During anesthesia, the NCAR group had a significantly greater need for vasoactive drugs to adequately maintain blood pressure. NCAR and CAR were similar in regard to intraoperative characteristics (ie, amount of administered fluids, type of surgery, use of minimally invasive technique, 
and duration of surgery and anesthesia). However, NCAR patients had greater blood loss, although it was not significant enough to necessitate the use of vasoactive drugs. AD decreases the cardiovascular compensatory response to the administration of anesthetics and surgical stress, facilitating hemodynamic instability. This finding is consistent with studies considering low HRV as a sensitive method for identifying blood pressure instability during GA. ${ }^{39,40}$ Huang et al reported that low TP may serve as an independent predictor of hypotension during GA, showing a significantly greater incidence of hypotension during GA in patients with diabetes mellitus. Interestingly, only a few of these patients had a diagnosis of CAN based on traditional autonomic tests (expiration:inspiration ratio, the Valsalva ratio, and standing $30: 15$ ratio) and suggested that spectral analysis of HRV is a sensitive method for detecting hemodynamic instability during GA ${ }^{39}$ Hanss et al confirmed that low TP has high sensitivity and specificity for predicting hypotension as well as bradycardia after the induction of GA in high-risk cardiovascular patients undergoing elective vascular or abdominal surgery. Moreover, they found a TP density cutoff value of $<500 \mathrm{~ms}^{2} \mathrm{~Hz}^{-1}$ for the prediction hemodynamic instability, ${ }^{40}$ but this value means extremely reduced HRV and is rarely used. Importantly, HRV is a useful method for identifying early stages of $\mathrm{AD}$ which cannot be diagnosed by traditional autonomic tests and when clinical symptoms of $\mathrm{AD}$ (ie, tachycardia at rest, orthostatic hypotension, constipation, neurological bladder, heat intolerance, etc.) may not be evident during routine preoperative assessment. ${ }^{38}$

We observed a significantly higher occurrence of postoperative complications in NCAR patients, including complications related to autonomic regulation (hypotension requiring vasoactive drugs and ileus). Increased use of vasoactive drugs in NCAR patients during and after GA confirmed one of the main problems of $\mathrm{AD}$ - an inability to maintain blood pressure during the perioperative period. The crucial mechanism for maintaining blood pressure stability is baroreflex. It is a feedback system comprising sensors (the baroreceptors), a processing unit (the central nervous system), and an output unit (autonomic nervous fibers). Baroreflex adjusts heart rate via both the vagal and sympathetic action, thus minimize short-term fluctuations in pressure. Baroreflex is involved in the modulation of spectral components (LF and HF) of HRV. Impaired baroreflex (measurement by baroreflex sensitivity - BRS) is closely associated with low HRV. ${ }^{8,41}$ Both decreased HRV and depressed BRS were confirmed as independent predictors of postoperative ischemia, myocardial infarction, cardiac arrest, and overall morbidity. ${ }^{20,21,25-27,42}$ Various measurements to evaluate ANS (triangular index, fractal scaling exponent $\alpha_{1}$, BRS) were used, but all studies confirmed the significant influence of ANS on cardiovascular homeostasis.

Postoperative ileus increases postoperative morbidity and is a cause of prolonged hospital stay after MAS. The complex pathophysiology of postoperative ileus involves several factors, including the degree of surgical trauma. However, $\mathrm{AD}$ is also an important factor in its development. ${ }^{43}$ In our study, NCAR patients had extremely reduced HF power (dominantly parasympathetic vagal activity) and LF power (sympathetic and parasympathetic influence). The reduced parasympathetic and sympathetic parts of the ANS represent serious $\mathrm{AD}$, the main reason for impaired gastrointestinal motility in NCAR.

We found significantly longer ICU-LOS and H-LOS in NCAR patients. These results are related to higher grade complications according to the Clavien-Dindo classification (grade $\geq$ III) in NCAR - that is, the number of reoperations and organ failures. This finding is consistent with another study in which decreased HRV was found to be a predictor of prolonged ICU stay in patients after coronary artery bypass grafting $(\mathrm{CABG})$ surgery and abdominal aortic surgery. ${ }^{18,19,24,25}$ However, variable parameters used for HRV assessment and time of own measurement (fractal scaling exponent $\alpha_{1}$, very low frequency [VLF] measurement during $24 \mathrm{~h}$, preoperative and postoperative measurements) were also used in these studies.

HRV was identified as a powerful predictor of long-term mortality, with $\mathrm{LF} / \mathrm{HF}$ ratio $<2$ and postoperative elevation of serum troponin I levels being independent predictors of 1 -year mortality in patients undergoing major non-cardiac surgery.22 The same authors investigated 2-year mortality and found that $\mathrm{LF} / \mathrm{HF}$ ratio $<2$ remained an independent predictor of mortality together with a history of heart congestion and age $>70$ years. ${ }^{23}$ These findings suggest that HRV measurement reflects physiological reserves necessary for recovery after hospital discharge. We evaluated LF/HF in the present study, but our values were different and we did not find significant differences in the LF/HF ratio between our study groups (except the supine-1 adaptive position). These findings may be due to different measurement methods. Our LF/HF ratios were calculated from measurements made during orthostatic load, which influenced the particular frequency band depending on the specific position. Moreover, our measurements were performed the day before surgery. Filipovic et al used LF/HF from a supine position immediately before induction of GA. Measurement in only one static 
position and psychological stress before surgery could have significantly influenced the LF and HF values. ${ }^{22,23}$

In clinical research of $\mathrm{HRV}$, various methods of analysis (time-domain analysis, geometric analysis, frequencydomain analysis, and entropy or fractal analysis), indexes, and units (absolute, logarithmic, standard units) have been used. Moreover, differences are present in the time and duration of measurements. No normative HRV values are currently, generally, accepted. ${ }^{44,45}$ As HRV is a very sensitive biosignal, high interindividual (age, gender, psychological stress during measurement, etc.) and intraindividual (circadian rhythm, food intake, smoking, etc.) variability can be obtained. ${ }^{46-48}$ Most chronic diseases manifest some degree of autonomic dysfunction. ${ }^{8,12-15}$ In addition, HRV measurements are influenced by the use of chronic medication. ${ }^{6-8,17}$ The use of some autonomic challenge (ie, the Valsalva maneuver or orthostatic load) can improve HRV measurement and better reflect the real degree of autonomic physiological reserves, in contrast to measurements under static conditions. ${ }^{10,11}$ In our study, we used orthostatic load which can help us identify patients without autonomic reactivity (NCAR) among elderly patients with comorbidities scheduled for MAS. NCAR was characterized by a plain chart of HRV patterns without reactivity in particular positions and low TP in the supine- 2 position (TP $<200 \mathrm{~ms}^{2}$ ). We used TP because it represents overall HRV, and we used TP from the supine-2 position because it showed the real status of autonomic regulation, especially due to uncovered vagal activity, which can be suppressed by psychological stress during evaluation in the supine-1 position. Moreover, vagal activity is reflexively augmented after laying down from standing to the supine-2 position. As a global parameter of HRV in the supine- 2 position, TP can be considered acceptable for quick determination of the real autonomic physiological reserves of patients.

This study has a few possible limitations: the small sample size and its being performed at a single center.

\section{Conclusion}

Preoperative assessment of autonomic physiological reserves based on HRV is important for the early identification of patients at high risk for the development of intraoperative and postoperative complications. This has the potential to influence perioperative clinical decision-making and eventually improve outcome. We suggest that standardized measurement of HRV during autonomic challenge be performed by anesthesiologists as routine perioperative practice. However, further research in the field is needed.

\section{Acknowledgments}

The authors thank Dr Rudolf Metelka and Professor Jaroslav Opavský from University Hospital Olomouc for advice on HRV measurement.

Michal Burda acknowledges partial support by the NPU II project LQ1602 "IT4Innovations excellence in science" provided by the Ministry of Education Youth and Sport, Czech Republic.

\section{Disclosure}

The authors report no conflicts of interest in this work.

\section{References}

1. Godin PJ, Buchman TG. Uncoupling of biological oscillators: a complementary hypothesis concerning the pathogenesis of multiple organ dysfunction syndrome. Crit Care Med. 1996;24(7):1107-1116.

2. Kenney MJ, Ganta CK. Autonomic nervous system and immune system interactions. Compr Physiol. 2014;4(3):1177-1200.

3. Máca J, Burša F, Ševčík P, Sklienka P, Burda M, Holub M. Alarmins and clinical outcomes after major abdominal surgery - a prospective study. J Invest Surg. 2017;30(3):152-161.

4. Pavlov VA, Wang H, Czura CJ, Friedman SG, Tracey KJ. The cholinergic anti-inflammatory pathway: a missing link in neuroimmunomodulation. Mol Med. 2003;9(5-8):125-134.

5. Tracey KJ. The inflammatory reflex. Nature. 2002;420(6917): 853-859.

6. Mustafa HI, Fessel JP, Barwise J, et al. Dysautonomia: perioperative implications. Anesthesiology. 2012;116(1):205-215.

7. McGrane S, Atria NP, Barwise JA. Perioperative implications of the patient with autonomic dysfunction. Curr Opin Anaesthesiol. 2014; 27(3):365-370.

8. Ernst G. Heart Rate Variability. 1st ed. London: Springer; 2014.

9. Metelka R. Heart rate variability - current diagnosis of the cardiac autonomic neuropathy. A review. Biomed Pap Med Fac Univ Palacky Olomouc Czech Repub. 2014;158(3):327-338.

10. Howorka K, Pumprla J, Jirkovska A, Lacigova S, Nolan J. Modified orthostatic load for spectral analysis of short-term heart rate variability improves the sensitivity of autonomic dysfunction assessment. J Diabetes Complications. 2010;24(1):48-54.

11. Deschamps A, Denault A, Rochon A, Cogan J, Pagé P, D'Antono B. Evaluation of autonomic reserves in cardiac surgery patients. J Cardiothorac Vasc Anesth. 2013;27(3):485-493.

12. Kleiger RE, Miller JP, Bigger JT Jr, Moss AJ. Decreased heart rate variability and its association with increased mortality after acute myocardial infarction. Am J Cardiol. 1987;59(4):256-262.

13. Maier P, Toepfer M, Dambacher M, Theisen K, Roskamm H, Frey AW. Heart rate variability and its relation to ventricular tachycardia in patients with coronary artery disease. Clin Sci (Lond). 1996;91:67.

14. Piepoli M, Coats AJ. Autonomic abnormality in chronic heart failure evaluated by heart rate variability. Clin Sci (Lond). 1996;91:84-86.

15. Vinik AI, Ziegler D. Diabetic cardiovascular autonomic neuropathy. Circulation. 2007;115(3):387-397.

16. Schmidt H, Hoyer D, Wilhelm J, et al. The alteration of autonomic function in multiple organ dysfunction syndrome. Crit Care Clin. 2008; 24(1):149-163.

17. Mazzeo AT, La Monaca E, Di Leo R, Vita G, Santamaria LB. Heart rate variability: a diagnostic and prognostic tool in anesthesia and intensive care. Acta Anaesthesiol Scand. 2011;55(7):797-811.

18. Laitio TT, Huikuri HV, Kentala ES, et al. Correlation properties and complexity of perioperative RR-interval dynamics in coronary artery bypass surgery patients. Anesthesiology. 2000;93(1):69-80. 
19. Stein PK, Schmieg RE Jr, El-Fouly A, Domitrovich PP, Buchman TG. Association between heart rate variability recorded day 1 and length of stay in abdominal aortic surgery patients. Crit Care Med. 2001; 29(9):1738-1743.

20. Mamode N, Docherty G, Lowe GD, et al. The role of myocardial perfusion scanning, heart rate variability and D-dimers in predicting the risk of perioperative cardiac complications after peripheral vascular surgery. Eur J Vasc Endovasc Surg. 2001;22(6):499-508.

21. Laitio TT, Huikuri HV, Makikallio TH, et al. The breakdown of fractal heart rate dynamics predicts prolonged postoperative myocardial ischemia. Anesth Analg. 2004;98(5):1239-1244.

22. Filipovic M, Jeger R, Probst $C$, et al. Heart rate variability and cardiac troponin I are incremental and independent predictor of oneyear all-cause mortality after major noncardiac surgery in patients at risk of coronary artery disease. J Am Coll Cardiol. 2003;42(10): 1767-1776.

23. Filipovic M, Jeger RV, Girard T, et al. Predictors of long-term mortality and cardiac events in patients with known or suspected coronary artery disease who survive major non-cardiac surgery. Anaesthesia. 2005;60(1):5-11.

24. Wu ZK, Vikman S, Laurikka J, et al. Nonlinear heart rate variability in CABG patients and the preconditioning effect. Eur J Cardiothorac Surg. 2005;28(1):109-113.

25. Laitio T, Jalonen J, Kuusela T, Scheinin H. The role of heart rate variability in risk stratification for adverse postoperative cardiac events. Anesth Analg. 2007;105(6):1548-1560.

26. Ushiyama $T$, Nakatsu $T$, Yamane $S$, et al. Heart rate variability for evaluating surgical stress and development of postoperative complications. Clin Exp Hypertens. 2008;30(1):45-55.

27. Scheffler P, Muccio S, Egiziano G, et al. Heart rate variability exhibits complication-dependent changes postsurgery. Angiology. 2013;64(8): 597-603.

28. Reimer P, Adamus M, Sklienka P, Ševčík P. Preoperative examination of the autonomic nervous system by measurement of heart rate variability for prediction of the periopeartive course. Anest Intenziv Med. 2015;26(3):137-144.

29. Dindo D, Demartines N, Clavien PA. Classification of surgical complications: a new proposal with evaluation in cohort of 6336 patients and results of a survey. Ann Surg. 2004;240(2):205-213.

30. Clavien PA, Barkun J, de Oliveira ML, et al. The Clavien-Dindo classification of surgical complications: five-year experience. Ann Surg. 2009;250(2):187-196.

31. Task Force of the European Society of Cardiology and the North American Society of Pacing and Electrophysiology. Heart rate variability. standard of measurement, physiological interpretation, and clinical use. Eur Heart J. 1996;17(3):354-381.

32. Pumprla J, Howorka K, Groves D, Chester M, Nolan J. Functional assessment of heart rate variability: physiological basis and practical applications. Int J Cardiol. 2002;84(1):1-14.
33. Eckberg DL. Sympathovagal balance: a critical appraisal. Circulation. 1997;96(9):3224-3232.

34. Hayano J, Sakakibara Y, Yamada A, et al. Accuracy of assessment of cardiac vagal tone by heart rate variability in normal subjects. Am J Cardiol. 1991;67(2):199-204.

35. Malliani A, Pagani M, Lombardi F. Physiology and clinical implications of variability of cardiovascular parameters with focus on heart rate and blood pressure. Am J Cardiol. 1994;73(10):3C-9C.

36. Howorka K, Pumprla J, Schabmann A. Optimal parameters of shortterm heart rate spectrogram for routine evaluation of diabetic cardiovascular autonomic neuropathy. J Auton Nerv Syst. 1998;69(2-3): 164-172.

37. Burgos LG, Ebert TJ, Asiddao C, et al. Increased intraoperative cardiovascular morbidity in diabetics with autonomic neuropathy. Anesthesiology. 1989;70(4):591-597.

38. Oakley I, Emond L. Diabetic cardiac autonomic neuropathy and anesthetic management: review of the literature. AANA J. 2011;79(6): 473-479.

39. Huang CJ, Kuok CH, Kuo TB, Hsu YW, Tsai PS. Pre-operative measurement of heart rate variability predicts hypotension during general anesthesia. Acta Anaesthesiol Scand. 2006;50(5):542-548.

40. Hanss R, Renner J, Ilies C, et al. Does heart rate variability predict hypotension and bradycardia after induction of general anaesthesia in high risk cardiovascular patients? Anaesthesia. 2008;63(2):129-135.

41. Wehrwein EA, Joyner MJ. Regulation of blood pressure by the arterial baroreflex and autonomic nervous system. Handb Clin Neurol. 2013;117:89-102.

42. Toner A, Jenkins N, Ackland GL; POM-O Study Investigators. Baroreflex impairment and morbidity after major surgery. Br J Anaesth. 2016; 117(3):324-331.

43. Holte K, Kehlet H. Postoperative ileus: a preventable event. Br J Surg. 2000;87(11):1480-1493.

44. Sandercock G. Normative values, reliability and sample size estimates in heart rate variability. Clin Sci (Lond). 2007;113(3):129-130.

45. Nunan D, Sandercock GR, Brodie DA. A quantitative systematic review of normal values for short-term heart rate variability in healthy adults. Pacing Clin Electrophysiol. 2010;33(11):1407-1417.

46. Stein PK, Kleiger RE, Rottman JN. Differing effects of age on heart rate variability in man and woman. Am J Cardiol. 1997;80(3):302-305.

47. Delaney JP, Brodie DA. Effects of short-term psychological stress on the time and frequency domains of heart rate variability. Percept Mot Skills. 2000;91(2):515-524.

48. Bonnemeier H, Richardt G, Potratz J, et al. Circadian profile of cardiac autonomic nervous modulation in healthy subjects: differing effects of aging and gender on heart rate variability. J Cardiovasc Electrophysiol. 2003;14(8):791-799.
Therapeutics and Clinical Risk Management

\section{Publish your work in this journal}

Therapeutics and Clinical Risk Management is an international, peerreviewed journal of clinical therapeutics and risk management, focusing on concise rapid reporting of clinical studies in all therapeutic areas outcomes, safety, and programs for the effective, safe, and sustained use of medicines. This journal is indexed on PubMed Central, CAS,

\section{Dovepress}

EMBase, Scopus and the Elsevier Bibliographic databases. The manuscript management system is completely online and includes a very quick and fair peer-review system, which is all easy to use. Visit http://www.dovepress.com/testimonials.php to read real quotes from published authors. 